\title{
Degradation of microcystins in aqueous solution with in situ electrogenerated active chlorine
}

\author{
Hong-Xing Shi ${ }^{\text {a,b }}$, Jiu-Hui Qu ${ }^{\text {a,* }}$, Ai-Min Wang ${ }^{\text {a,b }}$, Jian-Tuan Ge ${ }^{\text {a }}$ \\ ${ }^{a}$ State Key Laboratory of Environmental Aquatic Chemistry, Research Center for Eco-Environmental Sciences, \\ Chinese Academy of Sciences, Beijing 100085, China \\ ${ }^{\mathrm{b}}$ Graduate School of the Chinese Academy of Sciences, Beijing 100039, China
}

Received 9 August 2004; received in revised form 22 November 2004; accepted 25 November 2004

Available online 13 January 2005

\begin{abstract}
A new and efficient method for the degradation of microcystins (one family of blue algal toxins) was developed and studied. Microcystins (MCs) in water were directly and effectively removed by active chlorine transformed in situ from the naturally existing $\mathrm{Cl}^{-}$in water resource using electrochemical method. Titanium coated with $\mathrm{RuO}_{2}$ and $\mathrm{TiO}_{2}$ was used as the anode. Microcystin-RR (MCRR) and Microcystin-LR (MCLR) were chosen as the model compounds of MCs. The results suggested that $20.87 \mathrm{mg}^{-1}$ MCs (12.58 $\mathrm{mg}^{-1}$ MCRR and $8.29 \mathrm{mg}^{-1}$ MCLR) in aqueous solution with $1.85 \mathrm{~m} \mathrm{M} \mathrm{Cl}^{-}$could be synchronously decomposed within 15 min electrolysis under the condition of the current density $8.89 \mathrm{~mA} \mathrm{~cm}^{-2}, 20^{\circ} \mathrm{C}$ and $\mathrm{pH} 7.00$. The qualitative analysis showed that the heptapetide ring and the Adda group of both treated MCs were changed. The results also indicated that the removal rates of both MCs increased with the increasing of chloride concentration and applied current density, but decreased with the increasing of initial concentration of MCs and initial $\mathrm{pH}$ of electrolyte. In the absence of $\mathrm{Cl}^{-}$, only a small fraction of both $\mathrm{MCs}$ were decomposed by direct anodic oxidation, while their almost complete removals could be obtained in the case of indirect electrooxidation with in situ electrogenerated active chlorine from $\mathrm{Cl}^{-}$in water.
\end{abstract}

(C) 2004 Elsevier Ltd. All rights reserved.

Keywords: Microcystins; Microcystin-RR; Microcystin-LR; Electrochemistry; Degradation; Active chlorine

\section{Introduction}

Microcystins (MCs) are one family of the most frequently found cyanobacterial toxins in algae blooms from fresh waters. They are potent liver tumour promoters (Nishiwaki et al., 1992; Falconer and Humpage, 1996) and pose a major challenge for the production

\footnotetext{
* Corresponding author. Tel.: +8610 62849151; fax: +8610 62923558.

E-mail address: jhqu@mail.rcees.ac.cn (J.-H. Qu).
}

of safe drinking water from surface waters containing cyanobacteria. They have about 60 congeners with the general structure of cyclo-(D-alanine1-X2-D-MeAsp3Z4-Adda5-D-glutamate6-Mdha7) in which $\mathrm{X}$ and $\mathrm{Z}$ are variable $\mathrm{L}$ amino acids. Microcystin-RR (MCRR) and Microcystin-LR (MCLR) are two common MCs found in waters and their chemical structures are shown in Fig. 1. A provisional guideline value of $1.0 \mu \mathrm{g} 1^{-1}$ for total MCLR has been established by WHO (Chorus and Bartam, 1999).

Many methods for the removal of MCs have been reported. Conventional water treatment techniques 


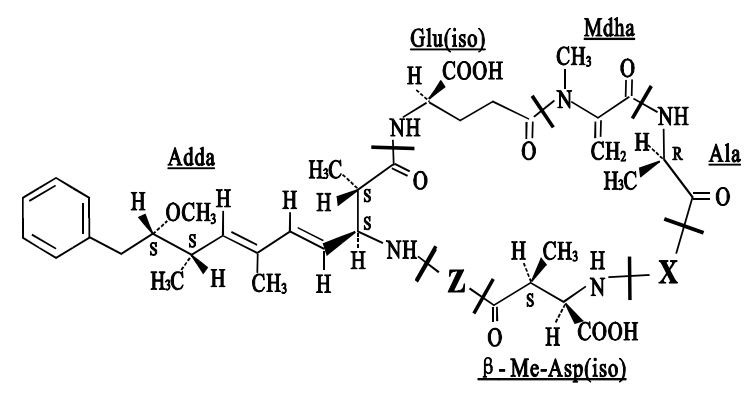

Microcystin RR: $X=\operatorname{Arg}(R), Z=\operatorname{Arg}(R)$

Microcystin LR: $\mathrm{X}=\mathrm{Leu}(\mathrm{L}), \mathrm{Z}=\operatorname{Arg}(\mathrm{R})$

Fig. 1. Chemical structure of MCRR and MCLR.

such as coagulation, sedimentation and filtration are not effective for removing MCs (Himberg et al., 1989). Activated carbon adsorption (Lambert et al., 1996), biotransformation (Angeline et al., 1995), chlorination (Nicholson et al., 1994; Tsuji et al., 1997), ozonation (Hoeger et al., 2002), ferrate (Yuan et al., 2002) and photocatalytic oxidation (Lawton and Robertson, 1999; Liu et al., 2003) have also been investigated (Hitzfeld et al., 2000). Very high concentrations of MCLR (50-200 $\mathrm{mg} \mathrm{l}^{-1}$ ) could be rapidly (10-40 min) destroyed using UV light in the presence of $1000 \mathrm{mg}^{-1}$ titanium dioxide catalyst (Robertson et al., 1997). Chlorination could be very effective at destroying MCLR and nodularin under conditions such that a chlorine residual of at least $0.5 \mathrm{mg}^{-1}$ was present after 30 min contact time (Nicholson et al., 1994). However, the effectiveness of the chlorine in reducing MCLR concentration was really dependent on $\mathrm{pH}$ and time. At $\mathrm{pH} 5$, removal was more than $93 \%$ within 30 min while the rate reached only $88 \%$ at pH 7 after $22 \mathrm{~h}$ oxidation (Croll and Hart, 1996; Hart et al., 1997).

In recent years, mainly because of the ease of control and the increased efficiencies, there has been great interest in the development of practical electrochemical methods such as anodic oxidation and indirect electrooxidation (Yang et al., 2000). It has been demonstrated that the addition of chloride ions in the electrolyte caused an increase in removal efficiency, and the complete degradation of pollutants can be achieved due to the participation of active chlorine, in the form of chlorine, hypochlorous acid and hypochlorite. The degradation of formaldehyde and 2-naphthol with in situ electrogenerated active chlorine has been performed successfully (Do and Yeh, 1995; Panizza and Cerisola, 2003).

The removal of MCs with the active chlorine electrogenerated from the naturally occurring chloride ions in water could have several advantages. Firstly, compared with other processes such as chlorination by the use of gaseous chlorine or concentrated hypochlorite solution, it is no need to add any chemicals into the water. Be- cause the chloride in naturally derived water can vary significantly between 10 and $250 \mathrm{mg}^{-1}$ or more, which gives an opportunity to use these unwanted $\mathrm{Cl}^{-}$to remove harmful MCs in water. Secondly, the hazards in handling these chemicals are also avoided because the in situ production of active chlorine may avoid the drawbacks of transport and storage of chlorine. In addition, while the unwanted $\mathrm{Cl}^{-}$naturally existing in waters is utilized to destroy the harmful $\mathrm{MCs}, \mathrm{Cl}^{-}$itself and some heavy metal cations such as copper, mercury, lead, can be removed partly. Finally, some MCs negatively charged can be continuously electro-migrated onto the surface of anode, and then be quickly oxidized by active chlorine transformed from $\mathrm{Cl}^{-}$. Therefore, oxidation with the active chlorine transformed from $\mathrm{Cl}^{-}$during electrolysis may be a promising method for MC removal from portable water.

This work investigated the efficacy of removing MCs in water with the electrogenerated active chlorine using a commercial DSA ${ }^{\circledR}$ electrode- $\mathrm{RuO}_{2}-\mathrm{TiO}_{2} / \mathrm{Ti}$ anode. In particular, the influence of some parameters such as chloride concentration, $\mathrm{pH}$, applied current density and MC concentration on the removal of MCRR and MCLR were reported.

\section{Materials and methods}

\subsection{Preparation of $M C s$}

The algal cells were collected in September of 2003 from Guanting Reservoir, one of the most important water resources of Beijing, China. After washed with water for three times, the cells were concentrated and frozen in $-20^{\circ} \mathrm{C}$ until required.

Before extraction, the frozen cells were thawed, then subjected to cell disruption and extracted two times with $50 \%$ methanol (including 50\% water) by ultrasound and continuous stirring for $30 \mathrm{~min}$ at room temperature. Adequate mixing was ensured during the process of cell disruption with the help of a magnetic stirrer. Then the extract was centrifuged at $12000 \mathrm{rpm}$ for $15 \mathrm{~min}$. A clarified supernatant rich in MCs was collected and methanol was removed from the supernatant by rotary evaporation to the water residue at $35^{\circ} \mathrm{C}$. The liquid concentrate was filtered through a Whatman GF/C filter and further cleaned up through a conventional SPE procedure using AccuBond ${ }^{\mathrm{II}}$ ODS-C18 cartridges $(500 \mathrm{mg}$ $3 \mathrm{ml}$, Agilent, USA) according to the literature methods (Rivasseau et al., 1998; Lawton and Edwards, 2001). The extracted and purified MCs were stored under $4{ }^{\circ} \mathrm{C}$ for use.

In this work MCRR and MCLR were found to two major congeners in the extracted MCs through comparison with the corresponding standard substances by HPLC-UV-PDA. 
Aqueous solutions of MCs were prepared by dilution with deionized water at room temperature. The contents of MCs were determined by high performance liquid chromatography (HPLC). The initial concentration of MCRR in experimental solutions was 3.14-12.58 $\mathrm{mg}^{-1}$ and that of MCLR was 2.07-8.29 $\mathrm{mg}^{-1}$.

\subsection{HPLC analysis}

The high performance liquid chromatograph was consisted of a Shimadzu (Kyoto, Japan) LC-10AD pump coupled to an SPD-M10A photodiode array detector system. Separations were accomplished under a ZORBAX SB-C18 column $(5 \mu \mathrm{m}, 4.6 \times 250 \mathrm{~mm}$, Agilent, USA) with a mobile phase of water containing $0.05 \% \quad(\mathrm{v} / \mathrm{v})$ trifluoroacetic acid (TFA)-acetonitrile

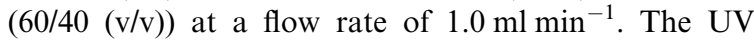
absorbance was monitored at $238 \mathrm{~nm}$ and sample injection volumes were $20 \mu 1$.

Standards of MCLR and MCRR were purchased from Alexis Co. (Sweden). All solvents and chemicals used in this study were HPLC or analytical grade. Distilled water was used throughout.

\subsection{Electrochemical oxidation process}

Schematic of the reactor used for MC degradation was shown in Fig. 2. Bulk oxidations were performed using an undivided glass cell with a volume of $50 \mathrm{ml}$, supplied with a magnetic stirrer with a constant stirring rate of $300 \mathrm{rpm}$. The typical $\mathrm{DSA}^{\circledR}$ electrode $\mathrm{RuO}_{2}-$ $\mathrm{TiO}_{2} / \mathrm{Ti}$ mesh with a working area of $9.0 \mathrm{~cm}^{2}$ was chosen as anode (The use of DSA type electrodes in large-scale water treatment systems could be favored by the accessibility of this technology from chlorine alkali plants.), the distance between two plates was $15 \mathrm{~mm}$. A dual

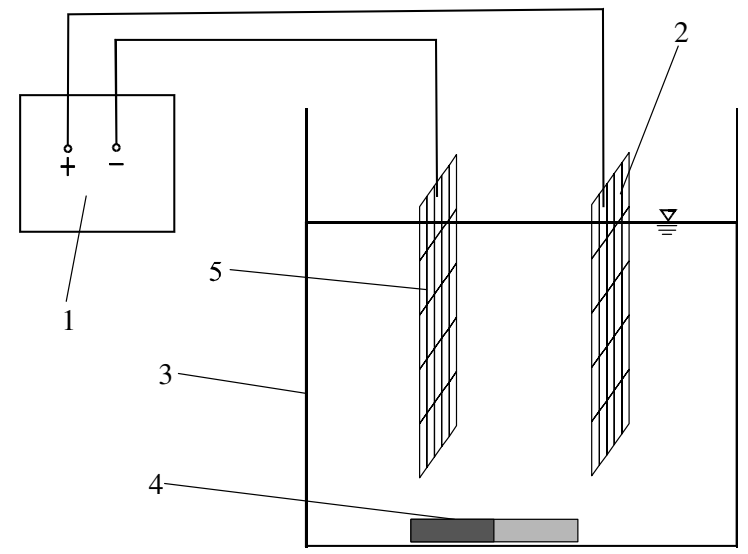

Fig. 2. Schematic of the reactor used for MCs degradation: (1) DC power supply; (2) $\mathrm{RuO}_{2}-\mathrm{TiO}_{2} / \mathrm{Ti}$ anode net; (3) undivided glass cell; (4) magnetic stirrer; (5) cathode plate.
DC potentiostat with a voltage of $0-32 \mathrm{~V}$ or a current of 0-5 A was employed as power supply for MC degradation. The treated volume of MCs was $40 \mathrm{ml}$ each time. Samples aliquots were taken at specific time intervals, filtered through a $0.45 \mu \mathrm{m}$ filter, and then immediately quenched with sodium thiosulfate for analysis by HPLC directly.

The electrochemical oxidation of MCs mediated by active chlorine was performed under different experimental conditions (e.g., content of $\mathrm{Cl}^{-}, \mathrm{pH}$, current density and concentration of MCs). Especially, in order to reveal whether the treatment process was suitable for treating potable water, $1.85 \mathrm{mM} \mathrm{Cl}^{-}$was selected in many cases, because it was a representative value of the concentration of $\mathrm{Cl}^{-}$in the Guanting Reservoir and was also lower than the maximum permissible $\mathrm{Cl}^{-}$ concentration in WHO standard value $250 \mathrm{mg}^{-1}$.

\subsection{Determination of chloride ion and active chlorine}

The overall concentration of dissolved chlorine in water was termed as the active chlorine, which was the sum of the three possible species, $\mathrm{Cl}_{2}, \mathrm{HClO}$ and $\mathrm{ClO}^{-}$. Its concentration was determined using DPD method. Chloride ion was analyzed by ion chromatogram method. In order to minimize the chlorine consumption, the solution for the determination of active chlorine was prepared using demonized water by adding $\mathrm{NaCl}$ (Kraft et al., 1999).

\section{Results and discussions}

\subsection{The efficacy and mechanism of MC degradation with electrogenerated active chlorine}

In order to observe the efficacy of the degradation of MCs by electrogenerated active chlorine, the HPLC chromatograms of the samples at different time in the process were compared in Fig. 3. The applied current densities were $8.89 \mathrm{~mA} \mathrm{~cm}^{-2}$, and the electrolyte included $1.85 \mathrm{mM} \mathrm{Cl}^{-}, 12.58 \mathrm{mg} \mathrm{l}^{-1}$ MCRR and $8.29 \mathrm{mg} \mathrm{l}^{-1}$ MCLR with pH 7.00 under $25^{\circ} \mathrm{C}$.

As shown in Fig. 3, the chromatogram of the MCs processed for 0 min presented two peaks due to MCRR and MCLR respectively at reservation time of $3.67 \mathrm{~min}$ and $7.22 \mathrm{~min}$. With the electrolysis process going on, the peaks of MCRR and MCLR decreased, which suggested the degradation of these MCs. MCRR and MCLR were reduced by $35 \%$ and $41 \%$ during the first $5 \mathrm{~min}$ of the electrolysis, and removed by $62 \%$ and $69 \%$ during the $10 \mathrm{~min}$ of the process, and almost completely degraded (>97\% reduction) within $15 \mathrm{~min}$.

The possible process of the degradation of MCs could be due to the electrogenerated active chlorine. Chloride ions negatively charged were continuously 


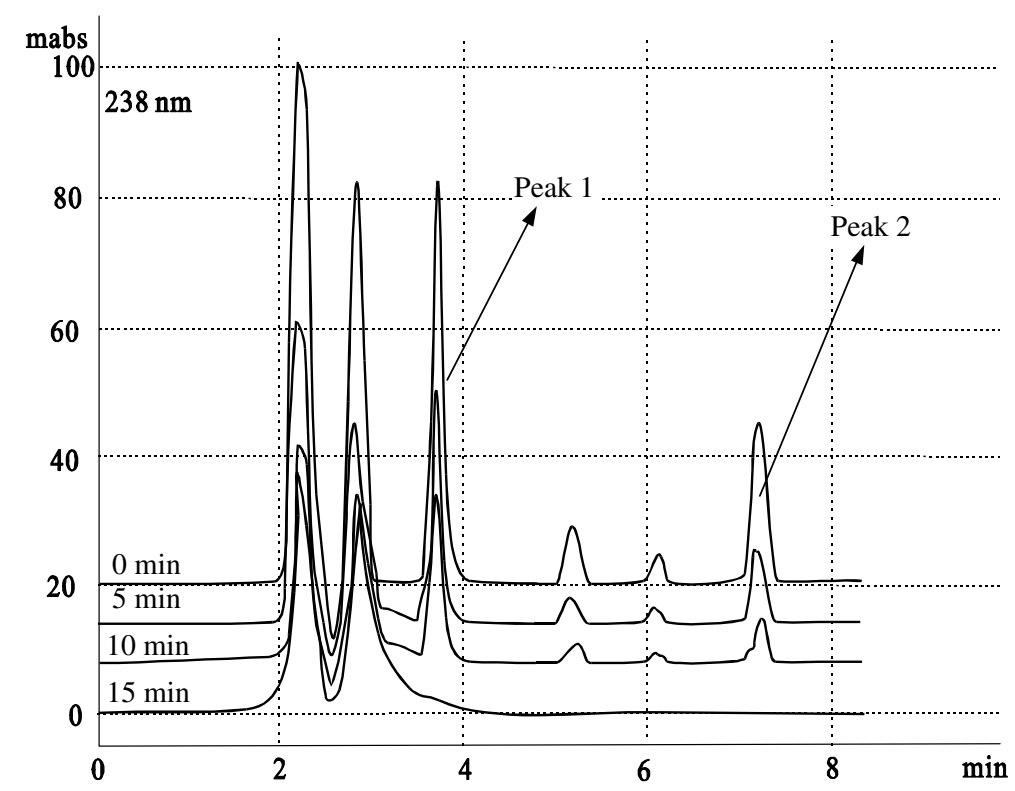

Fig. 3. High-performance liquid chromatograms (detection at $238 \mathrm{~nm}$ ) of the MCs during the degradation for: $0 \mathrm{~min}, 5 \mathrm{~min}, 10 \mathrm{~min}$, $15 \mathrm{~min}$. Electrolyte: initial MCRR $12.58 \mathrm{mg} \mathrm{l}^{-1}$; initial MCLR $8.29 \mathrm{mg} \mathrm{l}^{-1} ; 25{ }^{\circ} \mathrm{C}$; $\mathrm{pH} 7.00$; current density $8.89 \mathrm{~mA} \mathrm{~cm}^{-2}$.

electromigrated onto the anode surface, and quickly transformed to active chlorine in the form of chlorine, hypochlorous acid and hypochlorite, resulting in a surrounding with strong oxidation power near the anode surface (Kraft et al., 1999). On the other hand, MCLR negatively charged above pH 2.10 (Lawton et al., 2003) was continuously electromigrated near the anode surface, and quickly oxidized by active chlorine waiting there. Although MCRR was charge-neutral between $\mathrm{pH}$ 4 and 10 (Lawton et al., 2003), its high solubility in water acquired more chances of oxidation by active chlorine dissolved in bulk solutions. Thus, both MCRR and MCLR were easily decomposed by active chlorine transformed from $\mathrm{Cl}^{-}$.

Fig. 4 showed the changes of the concentrations of chloride ions and active chlorine during the electrolysis of dilute chloride solution prepared with deionized water. As shown in Fig. 4, on one hand, the concentration of $\mathrm{Cl}^{-}$was reduced during the first $5 \mathrm{~min}$ from $80.0 \mathrm{mg}^{-1}$ to $60.5 \mathrm{mg}^{-1}$ and then decreased slightly to $46.4 \mathrm{mg}^{-1}$ during the 40 -min process of electrolysis. The slightly reduce of chloride could be ascribed to the loss in the form of gaseous chlorine. On the other hand, the active chlorine was increased rapidly during the first $5 \mathrm{~min}$ from zero to $4.58 \mathrm{mg} \mathrm{l}^{-1}$ and remained stable thereafter. This proved the naturally existing $\mathrm{Cl}^{-}$in water resource could be effectively in situ transformed into active chlorine using a commercial DSA ${ }^{\circledR}$ electrode.

In order to discover the mechanism of MCs degradation by electrochemical oxidation, the HPLC chromatograms of absorption at $238 \mathrm{~nm}$ and $210 \mathrm{~nm}$ before and

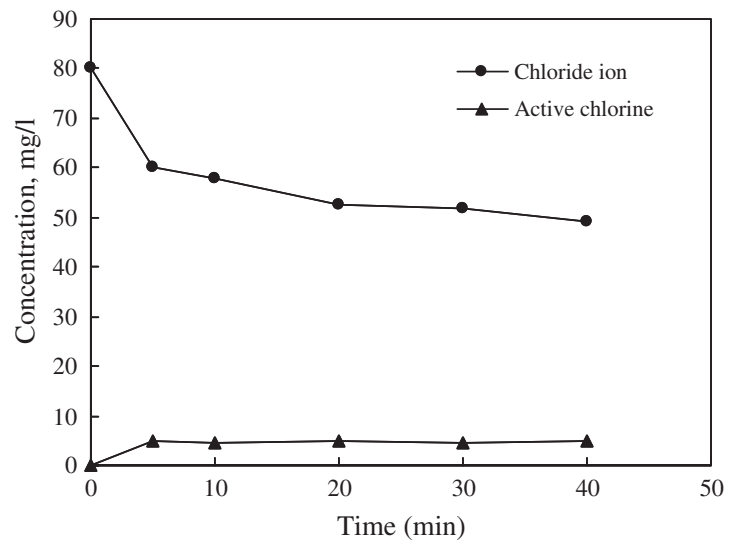

Fig. 4. Concentrations of chloride ions and total active chlorine during the electrolysis process.

after treatment were compared in Fig. 5. After treatment, both MCRR and MCLR were completely destroyed. The absorption around 238 assigned to Adda group disappeared, and that around $210 \mathrm{~nm}$ assigned to the loop decreased after treatment. These results suggested that when MCs were exposed to active chlorine during electrolyzing, not only the Adda bonds were cleaved by active chlorine, but also the loop was broken. The Adda group was the most unusual feature of MCs, which was essential for their activity and toxicity, and the stereoisomer at the Adda double bond has been reported to show no toxicity (Tsuji et al., 1997). 


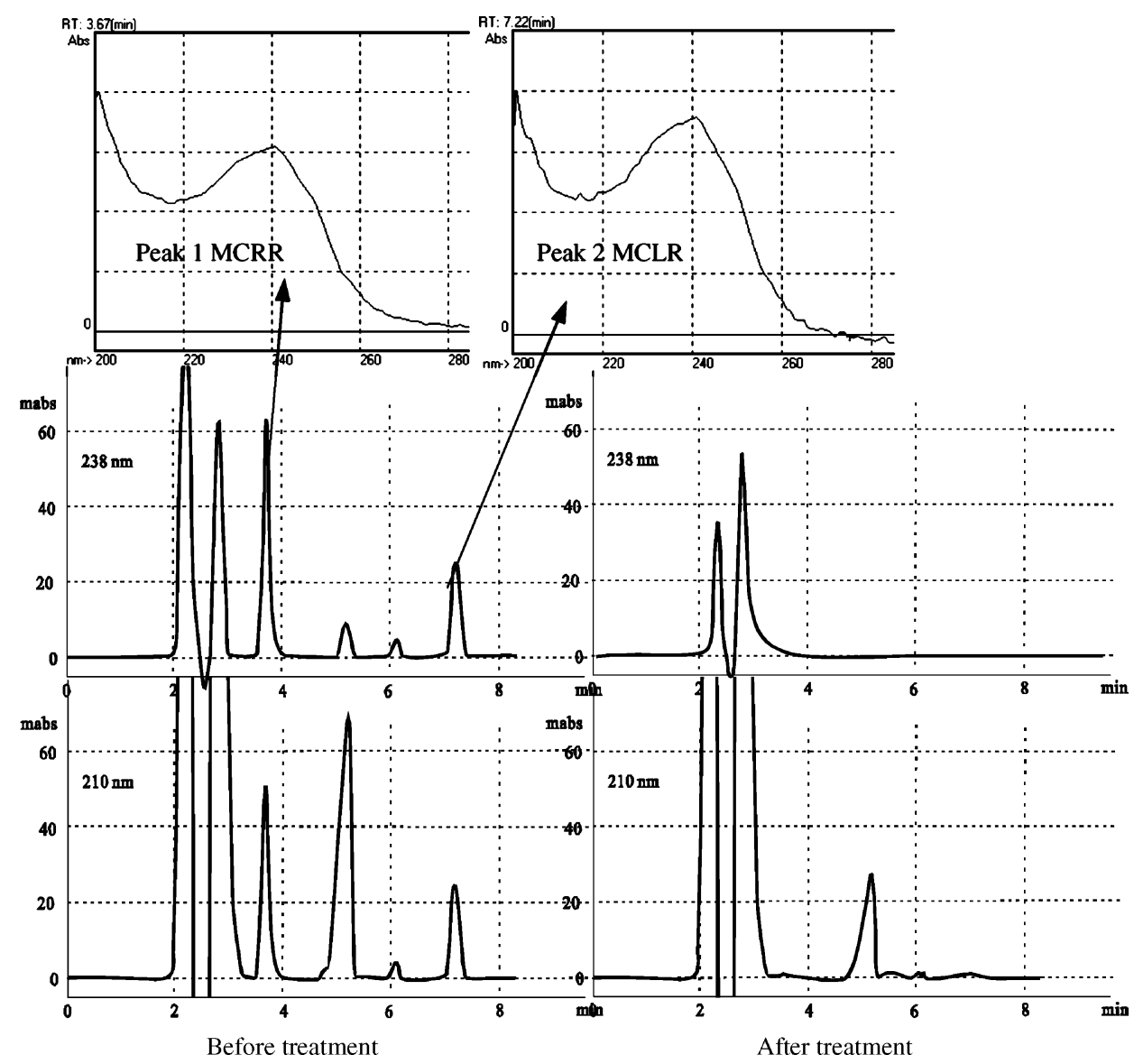

Fig. 5. Comparison of adsorption in $238 \mathrm{~nm}$ and $210 \mathrm{~nm}$ before and after treatment of MCRR and MCLR.

\subsection{Effect of initial concentration of $\mathrm{Cl}^{-}$in electrolyte}

To clarify the oxidation effect of active chlorine in electrochemical oxidation treatment of MCs, additional chloride was provided as the supporting electrolyte during the electrolysis. Fig. 6a illustrated the electrolysis results in terms of the concentration of MCs at various levels of chloride ions concentration in aqueous solution. The experiments were performed under the conditions: $0,1.85,20$ and $40 \mathrm{mM} \mathrm{NaCl}$, initial MCRR $12.58 \mathrm{mg} \mathrm{l}^{-1}$, initial MCLR $8.29 \mathrm{mg} \mathrm{l}^{-1}, 25^{\circ} \mathrm{C}, \mathrm{pH}$ 7.00, applied current density $6.67 \mathrm{~mA} \mathrm{~cm}^{-2}$.

As shown in Fig. 6a, the rates of degradation of both MCs rapidly increased with the increasing of concentration of $\mathrm{Cl}^{-}$. When no $\mathrm{NaCl}$ was used as supporting electrolyte, only a small fraction of both MCs were decomposed slowly by direct oxidation. However, the fast removals of both MCs were obtained in three cases of chlorine-mediated electrolysis and the removal rates of both MCs increased with the content of the initial $\mathrm{Cl}^{-}$. These results revealed that the addition of chloride had an enhancing effect on the electrochemical oxidation treatment of MCs.
By comparing the experimental results from the above supporting electrolytes, it was obvious that different mechanism of the degradation of MCs runs under the condition with $\mathrm{Cl}^{-}$and without $\mathrm{Cl}^{-}$. In the case without $\mathrm{Cl}^{-}$, the degradation of MCs is derived from direct oxidation of anode. But in the presence of $\mathrm{Cl}^{-}$, the concentration of $\mathrm{Cl}^{-}$became the key factor to influence the MCs removal, because of its effect on the production of active chlorine (Czarnetzki and Janssen, 1992; Yang et al., 2000). Therefore, the oxidation of active chlorine in bulk with $\mathrm{Cl}^{-}$played a more important role in the removal of MCs than direct one.

\subsection{Influence of initial $\mathrm{pH}$ of electrolyte}

To investigate the influence of $\mathrm{pH}$ on the effectiveness of the degradation, experimental runs were carried out at different initial $\mathrm{pH}$. The MC solution, containing $12.58 \mathrm{mg}^{-1}$ MCRR, $8.29 \mathrm{mg}^{-1}$ MCLR and $1.85 \mathrm{mM}$ $\mathrm{Cl}^{-}$, was still processed with a current density of $6.67 \mathrm{~mA} \mathrm{~cm}^{-2}$ at $25^{\circ} \mathrm{C}$. But the initial $\mathrm{pH}$ values were respectively adjusted to $4.0,4.98,7.00$ and 10.01 using 

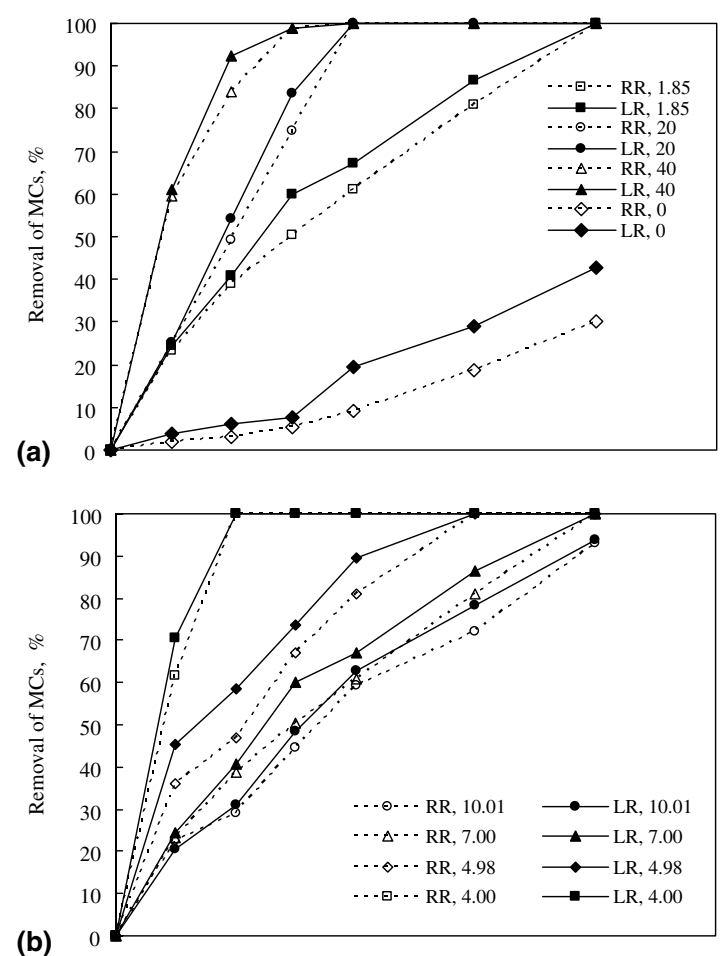

(b)
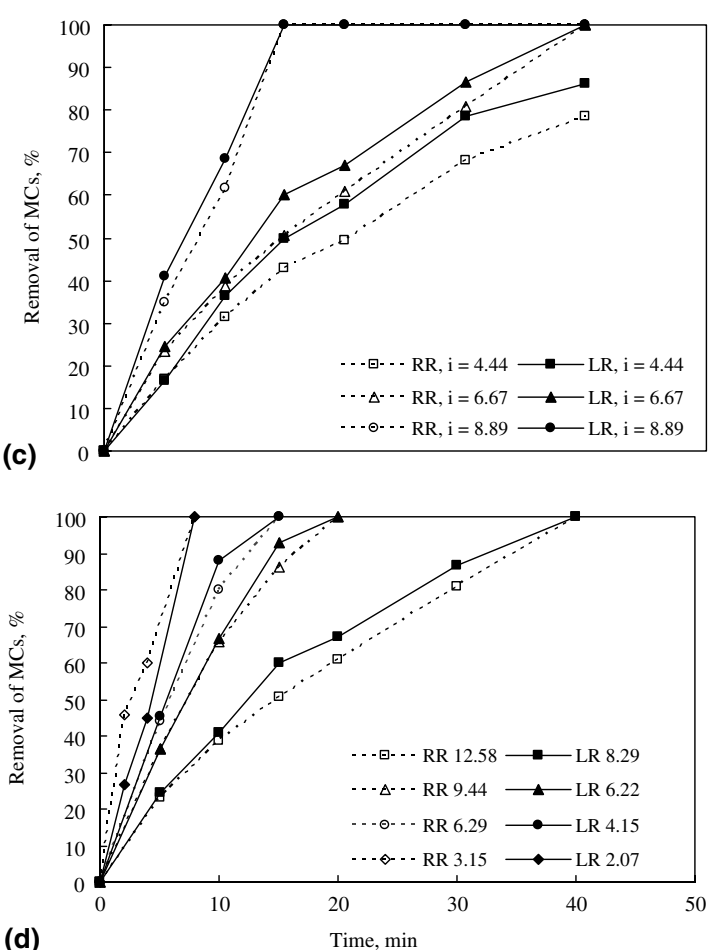

Fig. 6. Decomposition of $\mathrm{MC}$ at various conditions: (a) $\mathrm{Cl}^{-}$concentration: Electrolyte, initial MCRR $12.58 \mathrm{mg} \mathrm{l}^{-1}$; initial MCLR $8.29 \mathrm{mg} \mathrm{l}^{-1} ; 25^{\circ} \mathrm{C}$; $\mathrm{pH} 7.00$; current density $6.67 \mathrm{~mA} \mathrm{~cm}^{-2}$. (b) Various $\mathrm{pH}$ : Electrolyte, $\mathrm{NaCl} 1.85 \mathrm{mM}$; initial $\mathrm{MCRR}_{12.58} \mathrm{mg} \mathrm{l}^{-1}$; initial MCLR $8.29 \mathrm{mg} \mathrm{l}^{-1} ; 25^{\circ} \mathrm{C}$. (c) Various current density (i): Electrolyte, NaCl $1.85 \mathrm{mM}$; initial MCRR $12.58 \mathrm{mg} \mathrm{l}^{-1}$; initial MCLR $8.29 \mathrm{mg} \mathrm{l}^{-1} ; 25^{\circ} \mathrm{C}$; $\mathrm{pH} 7.00$. (d) Various initial concentrations of MCs: Electrolyte, $\mathrm{NaCl} 1.85 \mathrm{mM} ; 25^{\circ} \mathrm{C}$; $\mathrm{pH} 7.00$; current density $6.67 \mathrm{~mA} \mathrm{~cm}^{-2}$. 
$1 \mathrm{M}$ sulfuric acid or sodium hydroxide. The removal rates of MCRR and MCLR were respectively plotted in Fig. $6 \mathrm{~b}$ as a function of time.

As shown in Fig. 6b, with the decreasing of the initial $\mathrm{pH}$ of the MC solution, the rates of MCRR and MCLR both increased gradually. After processing for $15 \mathrm{~min}$, $45 \%$ MCRR and $48 \%$ MCLR were decomposed at the initial $\mathrm{pH} 10.01,51 \%$ MCRR and 60\% MCLR were removed at $\mathrm{pH} 7.00$, and $67 \%$ and $74 \%$ were done at $\mathrm{pH}$ 4.98. In the case of $\mathrm{pH} 4.00$, nearly $100 \%$ MCLR and MCRR were degraded within $15 \mathrm{~min}$.

$\mathrm{pH}$ value had a significant effect on the composition of active chlorine. Low $\mathrm{pH}$ was benefit to increase of the fraction of hypochlorous acid in the electrogenerated active chlorine. The hypochlorous acid was stronger oxidant and responsible for the degradation of the cyanobacterial toxins at $\mathrm{pH}<8$ (Nicholson et al., 1994). Our results also suggested that the degradation of MCs was increased at low $\mathrm{pH}$, tending to imply that the hypochlorous acid was important in the degradation of MCs.

\subsection{Improvement for MC degradation by regulating the current density}

The effect of current density on the removal of MCs as a function of electrolysis time was showed in Fig. 6c. The applied current densities were selected as 4.44, 6.67 and $8.89 \mathrm{~mA} \mathrm{~cm}^{-2}$ respectively. The electrolyte still included $1.85 \mathrm{mM} \mathrm{Cl}^{-}, 12.58 \mathrm{mg} \mathrm{l}^{-1}$ MCRR, $8.29 \mathrm{mg} \mathrm{l}^{-1}$ MCLR under $25^{\circ} \mathrm{C}$ and $\mathrm{pH} 7.00$.

As shown in Fig. 6c, with the increasing of the current density, the removal rates of both MCs increased rapidly. When current density was $4.44 \mathrm{~mA} \mathrm{~cm}^{-2}$, only $43 \%$ MCRR and 50\% MCLR were removed after $15 \mathrm{~min}$ treatment. When it increased to $6.67 \mathrm{~mA} \mathrm{~cm}{ }^{-2}$, $51 \%$ MCRR and $60 \%$ MCLR were removed; and it increased to $8.89 \mathrm{~mA} \mathrm{~cm}^{-2}$, the removals of both MCs reached nearly $100 \%$ within $15 \mathrm{~min}$.

Therefore, this nearly linear removal of MCs with current density could easily be used to control the process according to the changing of water quality in the practical use of electrochemical degradation of MCs.

In addition, increasing the operating current density promoted the generation of active chlorine from the electrochemical oxidation of $\mathrm{Cl}^{-}$(Burrows et al., 1978; Evdokimov and Gorodetskii, 1986). This fact indicated that the enhancement of MC removal due to the increasing current density was contributed by the indirect oxidation effect of active chlorine transformed from $\mathrm{Cl}^{-}$during electrolyzing. In high current density, more active chlorine produced. So, although there were some differences in composition of the amino acid and concentration of both MCs, little difference in both removal rates was observed. However in low current density, the difference between the removal rate of MCRR and MCLR was observed.
In fact, this difference could be ascribed to the practical difference in initial concentration of both MCs.

\subsection{Influence of MC concentration}

The results of experiments carried out at different initial concentrations of MCs were shown in Fig. 6d according to the concentration of both MCRR and MCLR as a function of reaction time respectively. The initial concentrations of MCRR were 3.15, 6.29, 9.44, $12.58 \mathrm{mg} \mathrm{l}^{-1}$ and those of MCLR were 2.07, 4.15, 6.22 and $8.29 \mathrm{mg}^{-1}$. These concentrations greatly exceeded those which occur naturally in eutrophic lakes or reservoirs. This, however, enabled us to directly quantify the toxins by HPLC, without multi-step processing which was necessary to quantify the much lower levels found in the environment. The electrolyte included $1.85 \mathrm{mM}$ $\mathrm{Cl}^{-}$with $\mathrm{pH} 7.00$ under $25^{\circ} \mathrm{C}$. An operating current density of $6.67 \mathrm{~mA} \mathrm{~cm}^{-2}$ was used.

As shown in Fig. 6d, the initial oxidation rates of MCs were influenced by their initial concentration and more rapid destruction was observed in the solution with lower concentration. It took $40 \mathrm{~min}$ to completely decompose $12.58 \mathrm{mg}^{-1}$ MCRR and $8.29 \mathrm{mg}^{-1}$ MCLR synchronously in water, but it took only 8 min to completely decompose $3.15 \mathrm{mg} \mathrm{l}^{-1}$ MCRR and $2.07 \mathrm{mg} \mathrm{l}^{-1}$ MCLR under the same conditions. Decreasing the initial concentration of MCRR in the aqueous phase from 12.58 to $8.41,5.28$ and $3.15 \mathrm{mg}^{-1}$ resulted in the increase of the initial oxidation rate of MCRR from $0.0231 \mathrm{~min}^{-1}$ to $0.0512,0.0685$ and $0.2500 \mathrm{~min}^{-1}$ respectively. And similarly, decreasing the initial concentration of MCLR from 8.29 to $6.22,4.15$ and $2.07 \mathrm{mg} \mathrm{l}^{-1}$, resulted in the increase of the oxidation rate of MCRR from $0.0236 \mathrm{~min}^{-1}$ to $0.0517,0.0687$ and $0.2500 \mathrm{~min}^{-1}$ respectively.

In fact, at concentrations below these shown, the rate of destruction was so rapid that MCs was undetectable by the first sampling point ( $2 \mathrm{~min}$ ). These data suggested that the much lower concentrations presented in drinking water would be rapidly removed.

\section{Conclusions}

This paper presented a new process for the removal of MCs in water. And the evidences were given about the possibilities of the degradation of MCs in aqueous solution with in situ electrogenerated active chlorine. The following conclusions were drawn:

1. The electrochemical process with in situ generated active chlorine using $\mathrm{RuO}_{2}-\mathrm{TiO}_{2} / \mathrm{Ti}$ anode was an extremely attractive removal method of $\mathrm{MC}$ in potable water. MCs of high content (12.58 $\mathrm{mg}^{-1}$ MCRR and $8.29 \mathrm{mg}^{-1}$ MCLR) in aqueous solution could 
be synchronously effectively decomposed within $15 \mathrm{~min}$.

2. The rates of MC degradation were found to increase with the increasing of chloride concentration in water. However, chloride ions as low as $1.85 \mathrm{mM}$ $\mathrm{NaCl}$ in portable water could be taken full advantage of in the process of MC degradation.

3. Increasing the applied current density from 4.44 to $8.89 \mathrm{~mA} \mathrm{~cm}^{-2}$ resulted in increasing removal of MCs.

4. Lower $\mathrm{pH}$ and lower initial concentration of MCs were beneficial to improve the degradation of MCs.

\section{Acknowledgments}

The authors appreciate the generous financial support of National Natural Science Foundation of China (No. 20337020), National Science Fund for Distinguished Young Scholars (No. 50225824), and the Practice Foundation of Chinese Academy of Sciences (for postgraduate).

\section{References}

Angeline, K.Y.L., Phillip, M.F., Ellie, E.P., 1995. Biotransformation of the cyanobacterial hepatotoxin microcystin-LR, as determined by HPLC and protein phosphatase bioassay. Environ. Sci. Technol. 29, 242-246.

Burrows, I.R., Denton, D.A., Harrison, J.A., 1978. Chlorine and oxygen evolution on various compositions of $\mathrm{RuO}_{2} /$ $\mathrm{TiO}_{2}$ electrodes. Electrochim. Acta 23, 493-500.

Chorus, I., Bartam, J., 1999. Toxic cyanobacteria in water. A guide to their public health consequences, monitoring and managements, WHO.

Croll, B., Hart, J., 1996. Algal toxins and customers. Paper presented at the UKWIR-AWWARF Technology Transfer Conference, Philadelphia.

Czarnetzki, L.R., Janssen, L.J.J., 1992. Formation of hypochlorite, chlorate and oxygen during $\mathrm{NaCl}$ electrolysis from alkaline solutions at a $\mathrm{RuO}_{2} / \mathrm{TiO}_{2}$ anode. J. Appl. Electrochem. 22, 315-324.

Do, J.S., Yeh, W.C., 1995. In situ degradation of formaldehyde with electrogenerated hypochlorite ion. J. Appl. Electrochem. 25, 483-489.

Evdokimov, S.V., Gorodetskii, V.V., 1986. Kinetics and mechanism of chlorine discharge and ionization at titanium-ruthenium oxide anodes. Sov. Electrochem. 22, 734742.

Falconer, I.R., Humpage, A., 1996. Tumour promotion by cyanobacterial toxins. Phycologia 35, 74-79.

Hart, J., Fawell, J.K., Croll, B., 1997. The fate of both intra and extracellular toxins during drinking water treatment. IWSA World Congress, Special subject No. 18, SS18-1-6. Blackwell Science, Oxford.

Himberg, K., Keijola, A.M., Hiisvirta, L., Pyysalo, H., Sivonen, K., 1989. The effect of water treatment processes on the removal of hepatotoxins from Microcystis and oscillatoria cyanobacteria: a laboratory study. Water Res. 23, 979-984.

Hitzfeld, B.C., Höger, S.J., Dietrich, D.R., 2000. Cyanobacterial toxins: removal during drinking water treatment and human risk assessment. Environ. Health Perspect. 108, 113122.

Hoeger, S.J., Dietrich, D.R., Hitzfeld, B.C., 2002. Effect of ozonation on the removal of cyanobacterial toxins during drinking water treatment. Environ. Health Perspect. 110 (11), 27-32.

Kraft, A., Stadelmann, M., Blaschke, M., Kreysig, D., Sandt, B., Schroder, F., Rennau, J., 1999. Electrochemical water disinfection Part I: hypochlorite production from very dilute chloride solutions. J. Appl. Electrochem. 29 (7), 859-866.

Lambert, T.W., Holmes, C.F.B., Hrudey, S.E., 1996. Adsorption of microcystin-LR by activated carbon and removal in full scale water treatment. Water Res. 30, 1411-1422.

Lawton, L.A., Edwards, C., 2001. Purification of microcystins. J. Chromatogr. A 912, 191-209.

Lawton, L.A., Robertson, P.K.J., 1999. Physico-chemical treatment methods for the removal of microcystins (cyanobacterial hepatotoxins) from potable waters. Chem. Soc. Rev. 28, 217-224.

Lawton, L.A., Robertson, P.K.J., Cornish, B.J.P.A., Marr, I.L., 2003. Processes influencing surface interaction and photocatalytic destruction of microcystins on titanium dioxide photocatalysts. J. Catal. 213, 109-113.

Liu, I., Lawton, L.A., Robertson, P.K.J., 2003. Mechanistic studies of the photocatalytic oxidation of microcystin-LR: an investigation of byproducts of the decomposition process. Environ. Sci. Technol. 37, 3214-3219.

Nicholson, B.C., Rositano, J., Burch, M.D., 1994. Destruction of cyanobacterial peptide hepatotoxins by chlorine and chloramine. Wat. Res. 28, 1297-1303.

Nishiwaki-Matsushima, R., Ohtake, T., Nishiwaki, S., Sukanuma, M., Kohyama, K., Ishikawa, T., Carmichael, W.W., Fujiki, H., 1992. Liver cancer promotion by the cyanobacterial cyclic peptide toxin microcystin-LR. J. Cancer Res. Clin. Oncol. 118, 420-424.

Panizza, M., Cerisola, G., 2003. Electrochemical oxidation of 2naphthol with in situ electrogenerated active chlorine. Electrochim. Acta 48, 1515-1519.

Rivasseau, C., Martins, S., Hennion, M.C., 1998. Determination of some physicochemical parameters of microcystins (cyanobacterial toxins) and trace level analysis in environmental samples using liquid chromatography. J. Chromatogr. A 799, 155-169.

Robertson, P.K.J., Lawton, L.A., Muench, B., Rouzade, J., 1997. Destruction of cyanobacterial toxins by semiconductor photocatalysis. Chem. Commun., 393-394.

Tsuji, K., Watanuki, T., Kondo, F., Watanabe, M.F., Nakazawa, H., Suzuki, M., Uchida, H., Harada, K.I., 1997. Stability of microcystins from cyanobacteria-IV, effect of chlorination on decomposition. Toxicon 35, 1033-1041.

Yang, C.H., Lee, C.C., Wen, T.C., 2000. Hypochlorite generation on $\mathrm{Ru}-\mathrm{Pt}$ binary oxide for treatment of dye wastewater. J. Appl. Electrochem. 30, 1043-1051.

Yuan, B.L., Qu, J.H., Fu, M.L., 2002. Removal of cyanobacterial microcystin-LR by ferrate oxidation-coagulation. Toxicon 40, 1129-1134. 